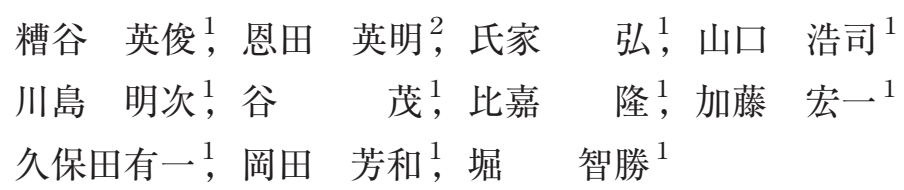

\section{Management of Poor Grade Subarachnoid Hemorrhage: Using Nicardipine Pellets}

Hidetoshi KasuYa, M.D., ${ }^{1}$ Hideaki Onda, M.D., ${ }^{2}$ Hiroshi UJIIE, M.D., ${ }^{1}$

Koji Yamaguchi, M.D., ${ }^{1}$ Akitsugu Kawashima, M.D., ${ }^{1}$ Shigeru Tani, M.D., ${ }^{1}$ Takashi Higa, M.D., ${ }^{1}$ Koichi Kato, M.D., ${ }^{1}$ Yuichi Kubota, M.D., ${ }^{1}$

Yoshikazu OKADA, M.D., ${ }^{1}$ and Tomokatsu HorI, M.D. ${ }^{1}$

${ }^{1}$ Department of Neurosurgery, Tokyo Women's Medical University, Tokyo, and

${ }^{2}$ Kofu Neurosurgery Hospital, Kofu, Japan

\author{
Key words: \\ - aneurysm \\ - poor-grade \\ - subarachnoid hemor- \\ rhage \\ - cerebral vasospasm
}

Surg Cereb Stroke

(Jpn) 34: 274-279, 2006

\footnotetext{
${ }^{1}$ 東京女子医科大学 脳神経外科, ${ }^{2}$ 甲府脳神経外科病院(受稿日 2005.11.24)(脱稿日 2005.1.20)〔連絡先：干162-8666 東京都新宿区河 田町 8-1 東京女子医科大学 脳神経外科 糟谷英俊] [Address correspondence: Hidetoshi KASUYA, M.D., Department of Neurosurgery, Tokyo Women's Medical University, 8-1 Kawada-cho, Shinjuku-ku, Tokyo 162-8666, Japan]
} 


\section{はじめに}

重症くも膜下出血の手術・管理の難しさは, 急性期に脳 浮腫が存在し，頭蓋内圧が高いことによる. 脳浮腫のため, 髄液 drainage をおいても手術が難しく，脳挫傷を作りや すい. そのため, さらに脳浮腫を助長させることになる77. また，脳浮腫のために，積極的な脳血管攣縮対策も困難と なる12)13). 一般的に用いられている hypervolemic hypertensive 療法は, 重症例に合併する脳浮腫, 肺水腫を助長 するため, 注意が必要となる，血管拡張薬の使用も慎重に ならざるを得ない，重症くも膜下出血では脳血管攣縮をい かに予防・治療していくかは重要な問題である.

ニカルジピン徐放剤 (nicardipine prolonged-release pellet, NP) は, イヌを用いた実験研究を経て，1999年の 10 月から東京女子医科大学の倫理委員会の承認のもと, これ までに 100 例以上のくも膜下出血患者に使用してきた。こ の経験から，ニカルジピン徐放剤の作用に関して明らかと 考えられる点は, (1) NPを目的の血管のそばに留置すると， この血管に攣縮は起こらない，(2)留置したNPから離れた 血管にはほとんど効果はない, (3)副作用は認めない, の 3 点である ${ }^{4)}$.

今回, 重症くも膜下出血の脳血管攣縮の予防・治療・管 理に焦点をあて，これまでわれわれの行ってきたニカルジ ピン徐放剤の効果について報告する.

\section{対象と方法}

\section{ニカルジピン徐放剤の作成}

PLGA (PLG1600 ML; molecular weight 4000, lactic acid ratio 0.5, Taki Co.)を $900 \mathrm{mg}$ と nicardipine free base $100 \mathrm{mg}$ を dichloromethane $10 \mathrm{ml}$ に溶解 し, dichloromethane 蒸発させ, 残りを乾燥させた。乾燥させた粉 $40 \mathrm{mg}$ を内径 $2 \mathrm{~mm}$ の Teflon tube に入れて stainless steel cylinderにて 35-40 度で加熱し， $100 \mathrm{~kg} / \mathrm{cm}^{2}$ で圧縮する。 こうしてできたペレットはnicardipine $4 \mathrm{mg}$ を含む. ガン マ線(日本照射サービス)にて滅菌を行った。この製剤の 薬物放出率などの検討に関しては，これまでの報告の通り である( ${ }^{4)}$.

\section{ニカルジピン徐放剤の適応基準と留置方法, 効果判定}

原則として，Fisher 分類 group $3 て ゙ ，$ 脳血管攣縮が起こ りそうな症例に使用する。急性期手術症例で, clippingに 続いて, 剝離した脳槽の, 脳主幹動脈 (内頸動脈, 前大脳 動脈，中大脳動脈)の脇に並べるようにして留置する，後 頭下開頭症例には用いない. 発症後 7-12 日に脳血管撮影 を行って，脳血管攣縮の程度を確認する。
Table 1 Clinical data for 34 poor-grade subarachnoid hemorrhage patients in 4 years (Oct. 1999-Sep. 2004)

\begin{tabular}{lll}
\hline & & No. \\
\hline Age & -60 & $16(9)$ \\
& -70 & $9(5)$ \\
WFNS grade & $71-$ & $9(7)$ \\
& 4 & $22(15)$ \\
CT on admission (Fisher) & 5 & $12(6)$ \\
& & \\
& Group 2 & $2(1)$ \\
Location of aneurysm & Group 3 & $29(20)$ \\
& Group 4 & 3 \\
Total & Anterior & $25(21)$ \\
& Posterior & 9 \\
\hline
\end{tabular}

I I indicates the number of patients treated with nicardipine pellets.

\section{治療方針}

くも膜下出血と診断した場合，脳幹反応の維持されてい る症例に対して根治手術を行う方針とした．外来にて挿管 し, 呼吸管理を行って, 脳血管撮影を行う。根治手術前に 髄液 drainage はおかない。 posterior circulationの脳動脈 瘤は, coiling を第一選択とした。開頭症例では, 手術中 脳室 drainage と頭蓋内圧 monitor をおく. 頭蓋内圧管理 は, 脳室 drainage, glycerin, mannitol などの浸透圧利尿 剤を全例で使用し，これでコントロールできない場合は， 外減圧術，barbiturate療法を用いる。早期より経静脈栄 養を使用し，低 albumin 血漿，貧血にはそれぞれ，albumin 製片，輸血を用いる，循環血液量を DDG analyzerを 用いて測定し, 循環血液量の維持に努める ${ }^{5)}$. Hypervolemia hypertension 療法は行わない.

\section{対象症例}

ニカルジピン徐放剤導入 (1999年 10 月) から 2004 年 9 月 までの 4 年間で経験した重症例について検討した. 根治術 を行ったくも膜下出血患者 125 例のうち, WFNS grade 4, 5 の重症例は 34 例，男性 13 例，女性 21 例，平均年齢は 62 （32-79）歳であった (Table 1)．21例に，開頭 clipping 後 に攣縮が起こりそうな血管 (IC, A1，2，3，M1，2，3)の脇に NP4-11本 (16-44 mg)を留置した. 6本までが8例，7-9本 が 9 例, 10 本以上が 4 例であった。また, 留置部位は, interhemispheric の $\mathrm{AC}(\mathrm{A} 1 \mathrm{~A} 2 \mathrm{~A} 3)$ が 5 例, 片側 の $\mathrm{AC}$ (A1A2) と MC (M1M2M3) 留置したのが 11 例，両側が 5 例であった，使用しなかったのは，coil 用いて瘤を処置 した椎骨脳底動脈瘤例 8 例, 脳内出血のみで脳血管攣縮の リスクが低いと考えられた 3 例, 脳浮腫がきわめて強く, 
Table 2 Nicardipine pellets used for 21 poor-grade patients

\begin{tabular}{lll}
\hline & & No. \\
\hline Exclusion & VA aneurysm (coiling) & 8 \\
& Severe edema & 2 \\
Total & Fisher group 4 & 3 \\
& & 13 \\
Number of pellets & -6 & 8 \\
& $7-9$ & 9 \\
Location of pellets placed & 4 \\
& AC (interhemispheric) & 5 \\
& Unilateral AC and MC & 11 \\
Total & Bilateral AC and MC & 5 \\
& & 21 \\
\hline
\end{tabular}

手術中延命は難しいと判断した 2 例であった（Table 2). 頭蓋内圧のコントロールに6 例で外減圧術, 8例で barbiturate療法を行った。

\section{結 果}

5例は, 7 日以内に死亡したため, 脳血管攣縮の評価は できなかった．これらはすべて NP非使用例であり，この うち 2 例は側頭葉の血腫が大きく手術後脳ヘルニアにより 死亡した. 3 例は coiling 症例であった。死亡例 5 例を除く 29 例のうち 2 例は手術後脳血管攣縮時期に脳血管撮影が 行われなかった. 27 例において, 脳血管撮影上の脳血管 攣縮を評価した，2例で強い脳血管攣縮を認め，このうち 1例が症候性となった. 11 例に軽度の脳血管攣縮を認めた。 残りの 14 例には脳血管攣縮は認めなかった. 脳血管攣縮 による脳梗塞は 1 例もなかった. 脳血管撮影を行っていな い2例では, 遅発性の神経症状は認めなかった。また, こ れらのうち NP を留置した症例 21 例 (20 例で脳血管撮影を 施行)では，1例で強い脳血管攣縮を認め，9例に軽度の脳 血管攣縮を認めた。残りの 10 例には脳血管攣縮は認めな かった．血管撮影上脳血管攣縮を認めたいずれの症例にお いても，NPをおいた近傍の血管には脳血管攣縮はなく， 若干拡張している場合もあった。症候性に到った例はなか ったＮ（によると考えられる副作用はなかった（Table 3).

急性期に肺炎の合併が 3 例, 静脈血栓症が 1 例, 腎機能 障害が 1 例にあった。開頭術, coiling の合併症は, 7 例 (20\%)に認めた。 その内訳は, clippingによる A2 の occlusion 1 例, perforator 障害 1 例, 脳の retractによる脳挫傷 2例, 静脈性梗塞 1 例, coiling による SCAの occlusion 1 例, 再出血1例であった。これら 34 例の転帰 (3カ月)は GR 7 例, MD 13 例, SD 7 例, V 2 例, D 5例であった (Table 4). grade 4 の 22 例では, independent rate
Table 3 Angiographical and clinical cerebral vasospasm in 34 poor-grade subarachnoid hemorrhage patients

\begin{tabular}{ll}
\hline Angiographical spasm & No. \\
\hline Severe & $2(1)$ \\
Mild & $11(9)$ \\
No & $14(10)$ \\
Not done & $7(1)$ \\
Total & $34(21)$ \\
\hline DIND & No. \\
\hline Yes & 1 \\
No & $28(21)$ \\
Not evaluated & 5 \\
Total & $34(21)$ \\
\hline
\end{tabular}

DIND indicates Delayed ischemic neurological deficits. ( ) indicates the number of patients treated with nicardipine pellets.

Table 4 Three-month outcome in 34 poor-grade patients

\begin{tabular}{lllllll}
\hline Grade & Good & MD & SD & Vegetative & Dead & Total \\
\hline 4 & $7(5)$ & $10(9)$ & 2 & $1(1)$ & 2 & $22(15)$ \\
5 & 0 & $3(1)$ & $5(5)$ & 1 & 3 & $12(6)$ \\
& & & & & & \\
Age & & & & & & \\
-60 & $4(3)$ & $7(5)$ & $3(1)$ & 0 & 2 & $16(9)$ \\
-70 & $2(2)$ & $3(2)$ & $1(1)$ & 1 & 2 & $9(5)$ \\
$71-$ & 1 & $3(3)$ & $3(3)$ & $1(1)$ & 1 & $9(7)$ \\
& & & & & & \\
Total & 7 & 13 & 7 & 2 & 5 & 34 \\
& $15)$ & $(10)$ & $(5)$ & $(1)$ & $10)$ & $(21)$ \\
\hline
\end{tabular}

( ) indicates the number of patients treated with nicardipine pellets.

(Good+MD) は 77\%で, grade 5 では $25 \%$ であった．年 齢別でみると， 60 歳まで， 70 歳まで，71歳以上の independent rateは，それぞれ，68\%，55\%，44\%であり，年 齢とともに，転帰は悪くなる傾向にあった，転㷌不良因子 は全例, 発症時脳損傷か, 手術あるいは coilingによる脳 損傷が合併したものと考えられた。実際の症例を図で示し た(Fig. 1, 2).

\section{考察}

今回の検討では, NP を使用した 21 症例に死亡例はなく， 脳血管攣縮による遅発性の虚血症状や脳梗塞をきたした症 例もなかった．脳血管撮影を行った 20 例のうち 1 例で強 い攣縮を認めたが, 残りは軽度の攣縮か, 攣縮は認めなか った. 血管撮影上脳血管攣縮を認めたいずれの症例におい ても，NPをおいた近傍の血管には攣縮はなかった。副作 


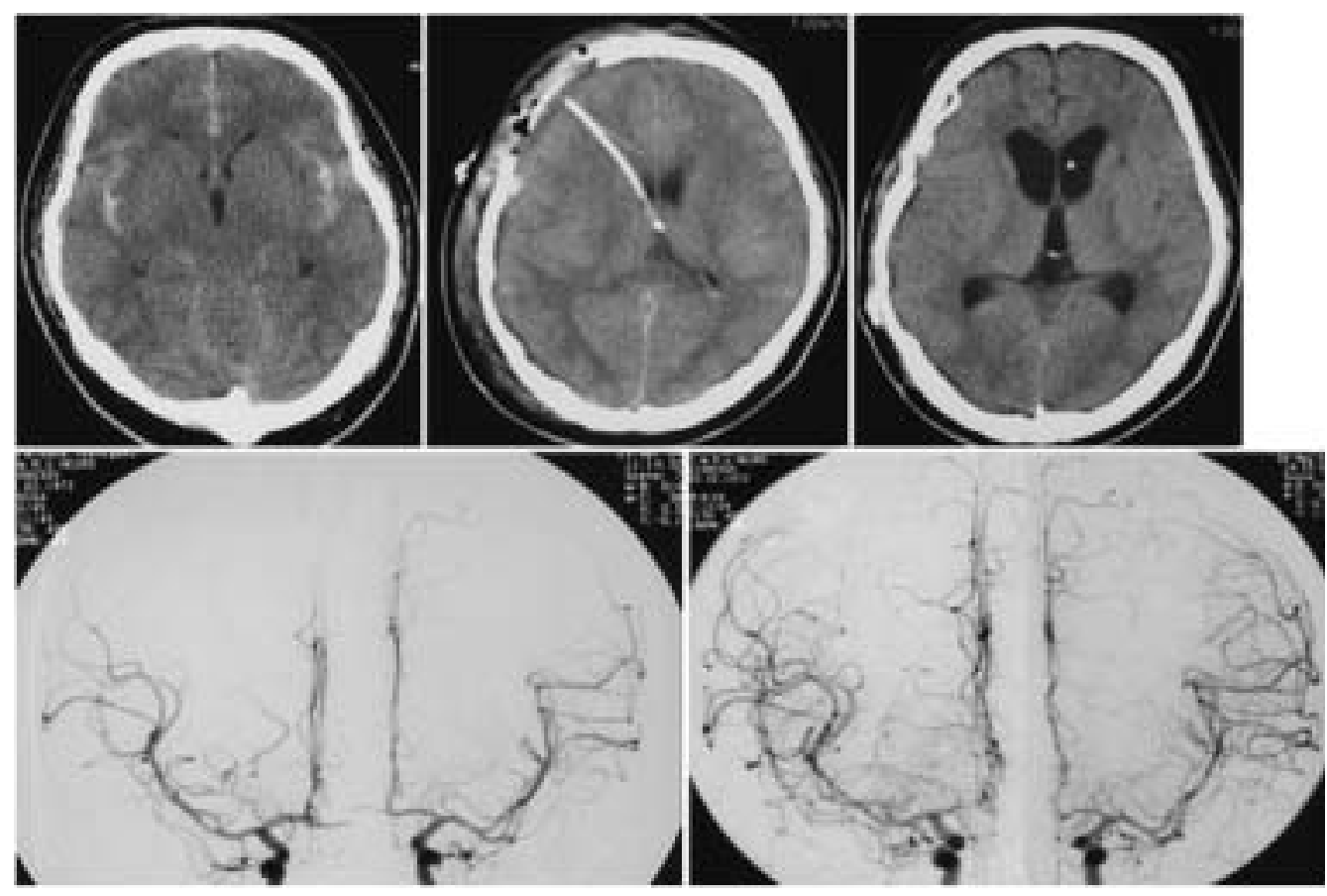

Fig. 1 A 32-year-old male patient (WFNS grade 4) underwent clipping of an anterior communicating artery aneurysm (lower leff) through a right pterional approach. 10 nicardipine pellets were placed along the right middle cerebral artery (MCA) (MI and M2) and the bilateral anterior cerebral artery (ACA) (A) and A2). The intracranial pressure was monitored and adjusted by the administration of glycerin, placement of a ventricular drainage, external decompression, and barbiturate therapy (upper middle). Angiography on day 8 showed no vasospasm (lower right); CT scan on day 30 showed no infarction (upper right). Outcome after 3 months: moderate disability.

用もなかった. 以上から, NPは重症くも膜下出血の脳血 管攣縮予防にもきわめて有効であるといえる．最終的な判 断は, randomized controlled trialを待たねばならないが, $\mathrm{NP}$ を留置した近傍の血管には脳血管攣縮は認めないこと からも, 効果は明らかである.

重症くも膜下出血の脳血管攣縮予防・治療は, 頭蓋内圧 の上昇のため，積極的に行う場合はリスクを伴う．脳血管 攣縮の原因であるくも膜下の血腫除去には, 手術で機械的 に除去する方法と urokinase などを還流させて溶かしだす 方法があるが，ともに重症例では難しい場合が多い。また， 脳血管攣縮治療として, hypervolemic hypertensive療法 は一般的に用いられているが, 頭蓋内圧を上昇させ, 肺水 腫などの合併症を悪化させる可能性がある ${ }^{12) 13)}$.また, 血管拡張薬の動脈内投与も, 急に頭蓋内の血管を拡張させ, 頭蓋内圧を上昇させる可能性がある. NP は脳血管攣縮が 起こりそうな血管の脇に留置するだけで，ほぼ確実にその 血管の脳血管攣縮を予防できる，頭蓋内圧を上昇させる心 配もない。

NP 療法にも限界があるのは事実である。まず，NPは 留置した脇の血管には効果があるが，離れた血管にはほと
んど効果がない．片側の Sylvius 裂に限局するくも膜下出 血はよい適応となるが，礵漫性に広がる血腫の場合には， 脳梗塞に到るような脳血管攣縮を予防できない可能性もあ る。また，今回，片側の pterional approach で両側の AC $\mathrm{MC}$ 領域に留置した症例が 5 例あったが, 特に, 重症で脳 浮腫がある場合には，留置することが脳挫傷などの合併症 を引き起こす可能性もでてくる．NPは開頭術を根治術に 選んだときのみに使用可能な薬剤である，最近では，重症 例には coiling を根治術として選択する場合も増えている. coiling を選んだ場合にはこの薬剤は使用できない.

今回のわれわれの治療成績は, 来院時に脳幹反応が存在 すればすべて根治術を行った場合の成績である，根治術を 行わなかった症例は全例死亡している.1990年，Bailesら の報告以来 ${ }^{1)}$, 重症くも膜下出血患者の手術適応決定に, 脳室 drainage をまず行い，症状改善がみられるか，脳圧 がコントロールできれば根治術を行うという方針をとる報

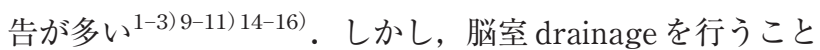
で，再出血を誘発することは明らかであり，われわれはこ の治療方針はとっていない2 ${ }^{237)}$. 重症例では drainageを おいても効果は一時的で，頭蓋内圧は変化がないとの報告 

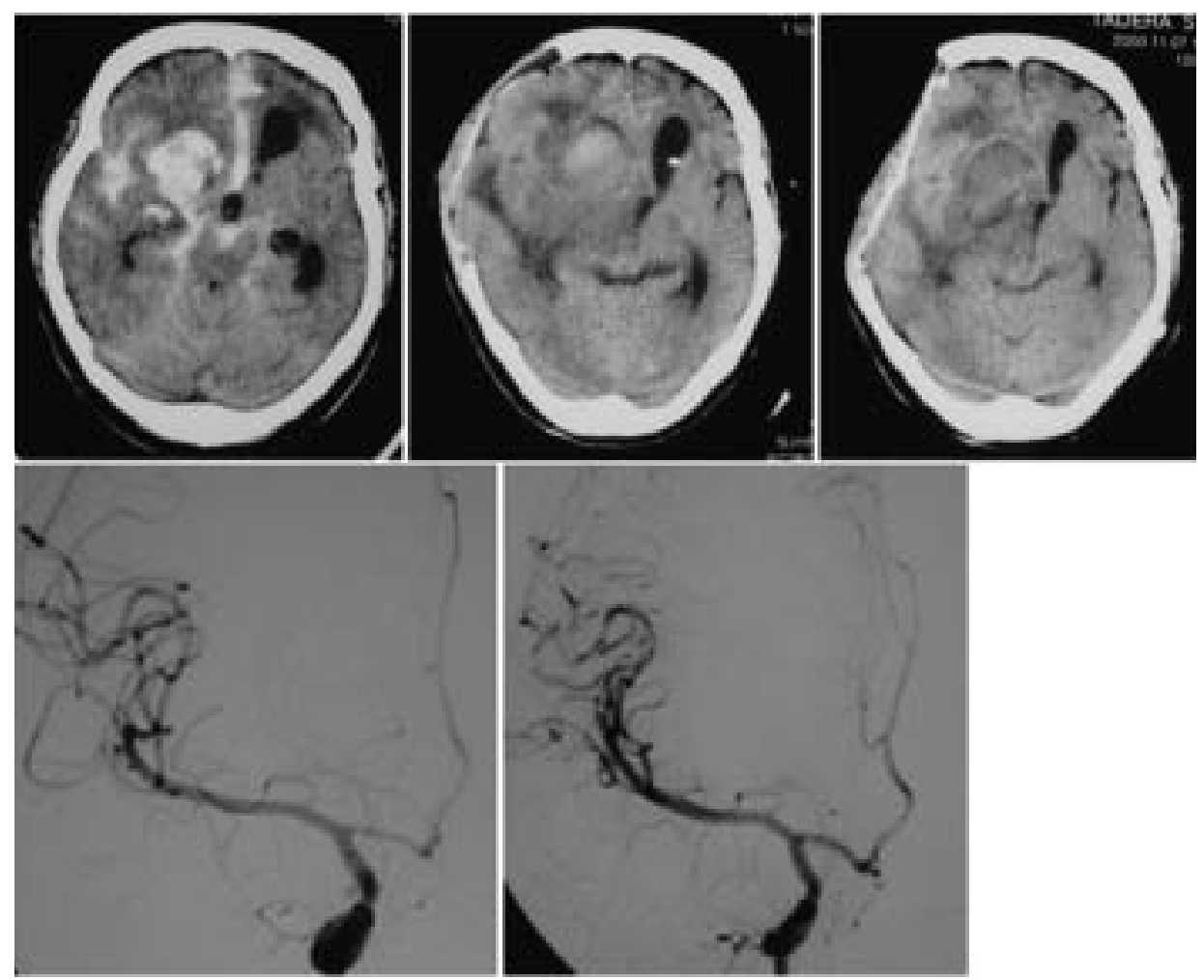

Fig. 2 A 54-year-old female patient (WFNS grade 5) presented with a thick clot in the right Sylvian fissure from a right internal carotid posterior communicating artery aneurysm (upper left, lower leff). Eleven pellets were placed at M1 bilaterally of the middle cerebral artery (MCA), at $\mathrm{A} 1$ and $\mathrm{A} 2$ of the anterior cerebral artery, and the right M2 of the MCA. The edema was so severe that decompressive craniectomy had to be performed (upper middle). On day 10 there was no vasospasm on angiography (lower right), on day 30 there was no infarction related to vasospasm (upper right). Neurological status after 3 months: severe disability.

もある7).これまでに controlled trial はないため, 症状の 改善は, drainageによるものなのか自然経過なのかはわ からない。

今回の検討では, grade 4 の治療成績は, independent rate $(\mathrm{GR}+\mathrm{MD})$ は $77 \%$ とほほ満足できる結果であった。 一方, grade 5 に関しては, GRはなく MDが $25 \%$ ので あった，積極的に治療しなかった症例は全例死亡していた が, grade 5 の治療適応については再考する必要がある ${ }^{11)}$.

今後，重症例では，根治術を選択する場合，開頭術によ る脳損傷を考慮して, coilingを選んだほうがよいかも知 れない. 実際, われわれも, 脳梗塞に到る脳血管攣縮が少 なく, 手術よりも coilingが容易と考えられる posterior circulation 脳動脈瘤に対しては, coiling を選択している. 幸い，脳血管攣縮による脳梗塞は経験しなかった. coiling を anterior circulation 症例にも第一選択とする場合は, こ の薬剤は使用できない, 脳血管攣縮は, 重症例に高率で合 併するわけではなく, 脳槽の血腫の量に比例する ${ }^{8)}$. その ため, NPは脳内血腫や，脳槽の血腫を手術的に除去する
必要がある症例や，手術が容易で脳血管攣縮の high risk 群にはよい適応となるだろう。

\section{結 論}

NPは重症くも膜下出血患者においても, 開頭手術を脳 動脈瘤根治術として選んだ場合, 脳梗塞をきたすような脳 血管攣縮を予防する，有用で安全な治療薬である。

ニカルジピン徐放製剂を実際に作成していただいてい る, 東京女子医科大学 薬剤部 製剤室 土谷隆紀先生と スタッフの方々に深謝いたします。

\section{文献}

1) Bailes JE, Spetzler RF, Hadley MN, et al: Management morbidity and mortality of poor-grade aneurysm patients. J Neurosurg 72: 559-566, 1990

2) Duke BJ, Kindt GW, Breeze RE: Outcome after urgent surgery for grade IV subarachnoid hemorrhage. Surg Neurol 50: 169-173, 1998

3) Gumprecht H, Winkler R, Gerstner W, et al: Therapeutic 
management of grade IV aneurysm patients. Surg Neurol 47: 54-59, 1997

4) Kasuya H, Onda H, Takeshita M, et al: Efficacy and safety of nicardipine prolonged-release implants for preventing vasospasm in humans. Stroke 33: 1011-1015, 2002

5) Kasuya H, Onda H, Yoneyama T, et al: Bedside monitoring of circulating blood volume following subarachnoid hemorrhage. Stroke 34: 956-960, 2003

6) Kasuya H, Onda H, Sasahara A, et al: Application of nicardipine prolonged-release implants: Analysis of 97 consecutive patients with acute subarachnoid hemorrhage. Neurosurgery 56: 895-905, 2005

7) Le Roux PD, Elliott JP, Newell DW, et al: Predicting outcome in poor-grade patients with subarachnoid hemorrhage: a retrospective review of 159 aggressively managed cases. J Neurosurg 85: 39-49, 1996

8) Macdonald RL, Rosengart A, Huo D, et al: Factors associated with the development of vasospasm after planned surgical treatment of aneurysmal subarachnoid hemorrhage. J Neurosurg 99: 644-652, 2003

9) Nowak G, Schwachenwald R, Arnold H: Early management in poor grade aneurysm patients. Acta Neurochir 126: 33-37, 1994

10) Rordorf G, Ogilvy CS, Gress DR, et al: Patients in poor neurological condition after subarachnoid hemorrhage: early management and long-term outcome. Acta Neurochir 139: 1143-1151, 1997

11) Seifert V, Trost HA, Stolke D: Management morbidity and mortality in grade IV and V patients with aneurismal subarachnoid haemorrhage. Acta Neurochir 103: 5-10, 1990

12) Shimoda M, Oda S, Tsugane $\mathrm{R}$, et al: Intracranial complications of hypervolemic therapy in patients with a delayed ischemic deficit attributed to vasospasm. $J$ Neurosurg 78: 423-429, 1993

13) Solenski NJ, Haley Jr EC, Kassell NF, et al: Medical complications of aneurysmal subarachnoid hemorrhage: A report of the multicenter, cooperative aneurysm study. Crit Care Med 23: 1007-1017, 1995

14) Spetzger U, Gilsbach JM: Results of early aneurysm surgery in poor-grade patients. Neurol Res 16: 27-30, 1994

15) Steudel WI, Reif J, Vogas M: Modulated surgery in the management of ruptured intracranial aneurysm in poor grade patients. Neurol Res 16: 49-53, 1994

16) Suzuki M, Otawara Y, Doi M, et al: Neurological grades of patients with poor-grade subarachnoid hemorrhage improve after short-term pretreatment. Neurosurgery 47: 1098-1105, 2000 